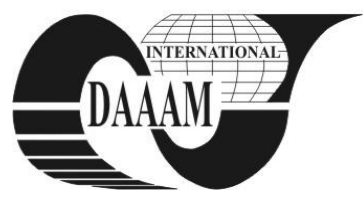

\title{
FACTUAL APPROACH TO DECISION MAKING IN COMPANIES SLOVAK REPUBLIK
}

\author{
KUCEROVA, M[arta] \& LESTYANSZKA SKURKOVA, K[atarina]
}

\begin{abstract}
The aim of any organization is to meet customer requirements while achieving the overall performance and capability of the organization. To fulfil these objectives basic principles of quality management were established, which include a factual approach to decision making. The strict application of these principles is a prerequisite for the long term success of the organization in a challenging competitive environment. This paper presents some results of a survey aimed at mapping the current state of the application of quality management principles in business practice in Slovakia. It refers to the important aspects relating to the decision of applied principles on the basis of facts, particularly in organizations with an established quality management system.

Key words: quality management, data analysis, measurement and monitoring, factual approach to decision making
\end{abstract}

\section{INTRODUCTION}

A quality Management System includes all the basic activities such as: quality planning, contracts review, purchasing, including verification of purchased products, identification and product traceability, management of process control and testing, management of nonconforming products, corrective actions and verification of their effectiveness, etc. The outcome of all these activities is data which has to be professionally processed and analyzed using various tools and methods. The actual level of the quality management system depends primarily on the quality of information obtained from different measurements, which is the task of deciding on the facts. Application of this principle in the business practice tends to be in making measurements and collecting data and information necessary to achieve the stated objective.

\section{THE POINT OF FACTUAL APPROACH TO DECISION MAKING}

In accordance with the decision making based on the facts, the organization has to define, plan and implement measurements and monitoring activities necessary to ensure conformity and to achieve improvement. This includes the identification of needs and use of appropriate methods including statistical techniques. The organization has to provide these activities to make sure that the monitoring and measurement activities that are necessary to ensure conformity and to achieve improvement are defined, planned and implemented.

The current requirements for quality management systems also require the application of new measurement processes which do not have the character of technical measures but the nature of the system, i.e. those who speak on the state of the quality management system. The measurement process is extended to the measurement and monitoring activities relating to performance of the quality management system and process performance, customer satisfaction, employee satisfaction and other concerned parties, , the costs relating to the quality and the like. The main objective of the procedural approach is to encourage efficiency and effectiveness of the organization in achieving the stated objectives (Nenadál, 2008).

From the factual approach to the decision making principle results for the effective decisions-making which are based on analysis of data and information. To successfully mange this principle it is necessary to ensure the following tasks in the organisation:

- collection of sufficiently accurate and reliable data from various processes in organizations,

- use of appropriate statistical methods of data collection and analysis,

- $\quad$ training people to use statistical methods in data collection and analysis,

- the willingness of managers to use analyzed data in decision making,

- if possible, making the results of data analysis accessible to the staff.

\section{APPLYING THE PRINCIPLE IN BUSINESS PRACTICE IN SLOVAKIA}

In the phase of transformation within our economy to a market economy, the industrial enterprises in Slovakia found themselves in a qualitatively new business environment, characterized by severe and rapid changes. Companies are forced to continually improve not only their products, but also their internal processes and systems to increase their competitiveness. (Bestvinová, 2006)

In this context we addressed the role of research aimed at the perspectives of development of quality management in relation to market requirements. Within the scope of the research project we conducted research to assess the current state of application of basic principles of quality management in 124 selected industrial enterprises in Slovakia.

The questionnaire was divided into eight groups according to individual principles of quality management. It was explicitly based on the principle of decision/making based on facts, their application in industrial practice in Slovakia were targeted by the following questions.

1. Is the systematic collection of data in your organisation ensured?

2. Does the management analyse the objectivity and reliability of data from individual processes?

3. Are the appropriate statistical tools for analysing and evaluating data used in your organisation?

4. Is the information from the collection and analyses of data available to all functions that need them to manage the processes?

5. How does the organisation use the results of data analysis obtained from the processes?

6. What do you consider to be the benefits of decisionmaking based on the facts? 
In evaluating the first question based on the data obtained we discovered, that there are significant differences in ensuring the collection of data among enterprises with an implemented quality management system compared with enterprises without a quality management system (Fig.1).

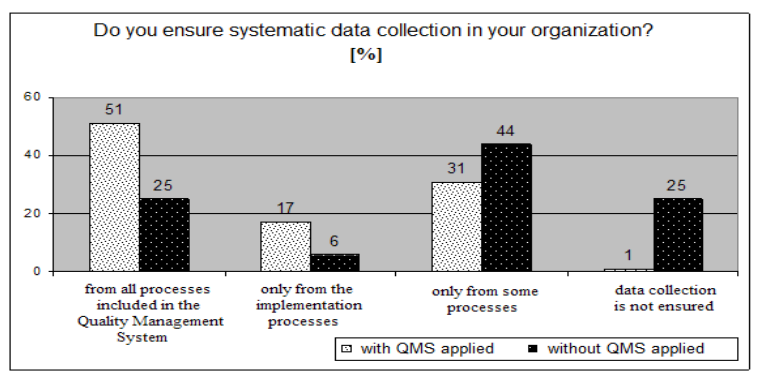

Fig. 1. Graphic representation of responses to the 1st question

Similar results were received from the second question which was aimed to find whether the management makes analysis of the objectivity and reliability of data from individual processes. In this area there appeared again, the significant differences among enterprises with an implemented quality management system and enterprises without a quality system as shown in the graph in Fig. 2.

The third question was aimed to determine whether the organizations use the appropriate tools and statistical methods in data collection, analysis and evaluation. Based on the survey we can conclude that this area is not addressed in the corporate practice at the required level. One of the reasons of this unfavourable state is the insufficient knowledge of statistical methods of the personnel concerned and their inability to use these methods. We have found that fact during our survey when analysing the principles of continuous improvement and its application in business practice. In most enterprises, the software support, regardless of the quality system, is used for data collection.

The Effective decisions must always be based on the analysis of data and information, which is based on facts. To put this principle in practice, it is necessary to take note of the data relating to quality management and other managerial systems and these must be available to all functions that need them, In organisations with an implemented quality management system, the necessary data is available for owners of the processes in $63 \%$ and in organisations without a quality system in only $31 \%$ cases. Thus also in this area are substantial difference among analysed organisations.

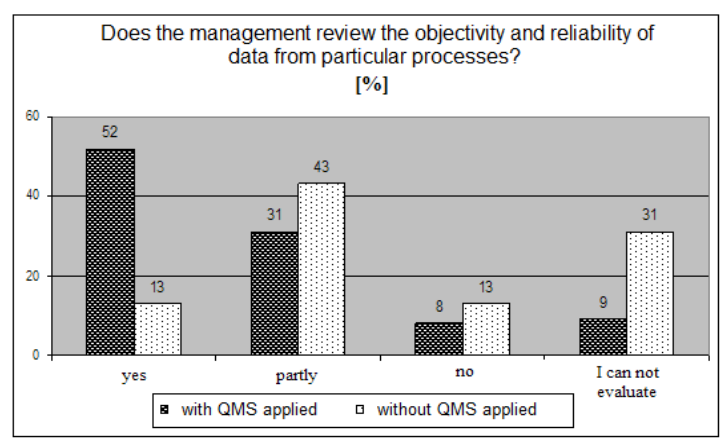

Fig. 2. Graphic representation of responses to the 2nd question

The answers to the question: How does the organisation use the results of data analysis obtained from the processes?

Were the following responses in this order, according to the number of responses:

1. for improvement of processes.

2. for setting targets for quality,

3. as a base for management review,
4. for the planning of financial resources within the quality management system.

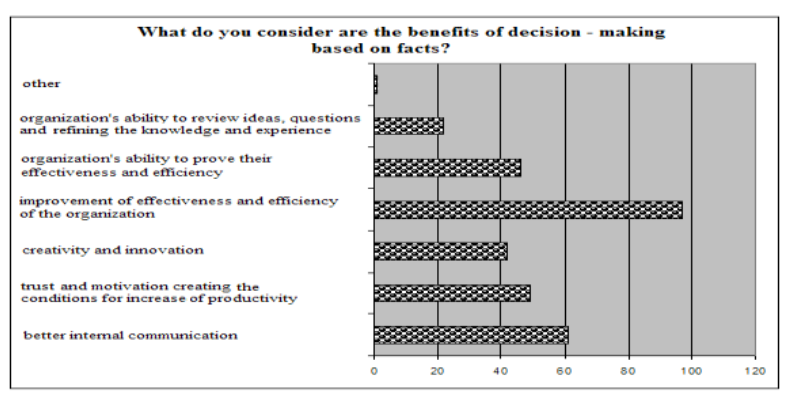

Fig. 3. Graphic representation of responses to the 6th question

The survey reveals that policy decision based on facts is especially reflected in the field of measuring, monitoring and improvement. All these activities are very closely related to the analysis of data, which cannot be made without competent and proper decisions. The obligation of each organisation that has implemented a quality management system is the implementation of continuous quality improvement through the improvement of all processes and activities which contribute to improving the efficiency and effectiveness of QMS and the organisation in general.

These facts can also be seen within the result of the following question which was focused on the benefits from decision making based on facts. In this case, respondents had to specify three most important areas; this question's results are expressed in the form of absolute frequencies. As shown in Fig. 3, expressing the largest considered benefit as improvement, efficiency and effectiveness of the organization.

Executives must be able to provide and also use the objective information from a quality management system in the decisionmaking processes. They have to be aware of the trends in the development of indicators, of the efficiency of these systems and objectively estimate the areas of further development. These facts require greater demands on workers` knowledge of various methodologies and procedures for measurement, whether technical or systemic. (Paulová, 2010)

\section{CONCLUSION}

The principle of deciding on the basis of the facts is the eight quality management principle. Based on the survey we investigated the application of this principle in business practice and we compared the differences of its application in various industries in Slovakia. We specified the important aspects which have become subject towards the further solution of our research project. Data analysis is therefore necessary to assure that the quality management system is effective and that in the process there are identified places where it is necessary to make data collection and analysis to ensure quality.

\section{REFERENCES}

Bestvinová,V.(2006). Application of controlling in business practice, In: Forum of manager, No 1. 2006, pp 62-64, ISSN 13367773, Trnava

Nenadál, J. (2008). Modern quality management. Management Press, 2008, ISBN 978-80-7261-186-7, Praha

Paulová, I. (2010). Perspectives of quality management development in relation with requirements of market in Slovak republic, AlumniPress, ISBN 978-80-8096-129-9, Trnava

ISO 9001:2008, Quality Management Systems - Requirements.

ISO TS 16949 QMS - Particular requirements for the application of ISO 9001:2000 for automotive production and relevant service part organizations 